\title{
AOR
}

Selected Papers of \#AoIR2018:

The $19^{\text {th }}$ Annual Conference of the

Association of Internet Researchers

Montréal, Canada / 10-13 October 2018

\section{"EVERY WORD YOU JUST SAID IS WRONG": ONLINE RAGE AND INCLUSIVITY IN DISNEY FRANCHISE FANDOM}

\author{
Bridget Blodgett \\ University of Baltimore \\ Anastasia Salter \\ University of Central Florida
}

\begin{abstract}
The months leading up to the release of Disney franchise films The Last Jedi (December 2017) and Black Panther (February 2018) were marked by speculation, concern, and fervor in equal measures from the established fan communities of Star Wars and Marvel. Both franchises have been associated with toxic geek masculinity, a performed, communal hypermasculinity marked by exclusionary practices and rhetoric (Salter \& Blodgett, 2017). By centering either non-white or non-male characters as leads in roles traditionally dominated by cisgender white men, both films became centers for toxic discourse and targeted campaigns aimed at disrupting their commercial success. In this paper, we will situate these case studies as emblematic of the changing discourse of geek fandom spaces, and its intersections with white supremacy and misogyny.
\end{abstract}

\section{Toxic Geek Masculinity in Online Spaces}

The growing visibility of toxic geek masculinity has been studied through a number of cases: most notably, the GamerGate movement (organized by an ex-partner as an attack on a woman whose games achieved critical attention, but quickly escalating to target a number of women in game design and games communities) became a central rallying point for both misogynist and white supremacist trolling and harassment (Chess \& Shaw, 2015; Massanari, 2017; Braithwaite, 2016). While the discourse of hypermasculinity in geek-centered communities, and indeed more broadly online,

Suggested Citation (APA): Blodgett, B. \& Salter, A. (2018, October 10-13). "Every Word You Just Said is Wrong": Online Rage and Inclusivity in Disney Franchise Fandom. Paper presented at AolR 2018: The $19^{\text {th }}$ Annual Conference of the Association of Internet Researchers. Montréal, Canada: AolR. Retrieved from http://spir.aoir.org. 
significantly predates that incident (Salter \& Blodgett, 2012; Kendall, 2002), the increased organization and visibility of exclusionary and violent rhetoric from within these spaces has led to wider attention.

These films share qualities that make them ideal for a comparative case study: both are films with established fanbases invested in the success of the franchise, but accustomed to certain models of representation. While The Last Jedi does center nonwhite actors in major roles (and includes a notable sequence where no white men are on screen for a considerable time), it has ultimately not attracted the same attention from white supremacists as Marvel's Black Panther. Demographically, Black Panther is nearly the opposite of previous films in the franchise, which have primarily featured black characters in sidekick roles--not as stereotyped as previous superhero franchises, but very far from leading roles (Claverie, 2017).

\section{Methods}

This article is a case study analysis of the fan discourse and social media centered attempts to disrupt the success and perceived viability of these two major franchise films. Given both the attempts by participants to conceal their objectives or authenticity, and the situated nature of these attacks on platforms including Twitter, Metacritic, and Rotten Tomatoes, it is necessary to examine them contextually and consider the influence of the platforms and their affordances on the discourse (Yin, 2003). As the film's releases were relatively close in temporal proximity, the examined discourse spans October 2017 to February 2018. Sampled primary texts include news articles, blog posts, tweets, and fan reviews.

\section{Case Study: The Last Jedi and Black Panther}

After reviewing the discourse from October 2017 to February 2018, we inductively categorized as relating to one of three themes: rejection of the film as a text; and threats to cast members, creators, or fans of the film. Rejection of the film was the most widespread in both: as of February 28, 2018, a petition by Henry Walsh hosted on change.org to "Have Disney strike Star Wars Episode VIII from official canon" has nearly 100,000 signatures united by the call to "Let us keep our heroes" (Walsh, 2017). Criticism of Black Panther, by contrast, frequently includes a rhetorical move of suggesting the film is only achieving critical success because of its cast or resorts to outright racist language:

Didn't care for it, lieing [sic] about how good this is because of racial emotional pride is the only logical answer. I want my $\$ 14$ back, was not worth it and my 2 friends felt the same way. $\$ 14$ bucks thats almost a case of beer right there! :( (YouTube comment, February 25, 2018)

BLACK panther 2: Rise of the cotton pickers... may of 2020!! you heard it here first (YouTube comment, February 28, 2018) 
In both cases, the same Facebook group (entitled "Down With Disney's Treatment of Franchises and its Fanboys") organized an event and claimed credit for efforts to lower the audience score of the film, explaining to one reporter that they were responding to Disney's attempt to "shove SJW messages down our throats" (Plante, 2018).

The most disturbing and widely reported campaign to disrupt one of the films through violence was targeted at Black Panther. On the day of the film's release, a number of messages appeared throughout social media featuring apparent attacks on white attendees of the premiere:

I went to see \#BlackPanther with my gf and a black teenager shouted ' $u$ at the wrong theater' and smashed a bottle on her face (Twitter, @AsianWifeHaver, February 16, 2018)

These types of tweets featured images pulled from existing violence (in the case of the above tweet, the image was sourced from the documentation of a domestic battery), and while they were quickly debunked the stories continued to circulate (Romano, 2018).

\section{Conclusion}

The incredible commercial success of Black Panther cannot be denied: only a few weeks into its run, the film was declared a domestic success, passing all but a few previous Marvel hits in the box office (Mendelson, 2018). Both films suffered from a marked discrepancy in audience ratings versus general critical acclaim on Rotten Tomatoes which may have impacted their success, but it is difficult to measure any impact of these campaigns on potential viewers (Mendelson, 2018).

\section{References}

Braithwaite, A. (2016). It's about ethics in games journalism? Gamergaters and geek masculinity. Social Media+ Society, 2(4), 2056305116672484.

Chess, S., \& Shaw, A. (2015). A conspiracy of fishes, or, how we learned to stop worrying about\# GamerGate and embrace hegemonic masculinity. Journal of Broadcasting \& Electronic Media, 59(1), 208-220.

Claverie, E. (2017). Ambiguous Mr. Fox: Black Actors and Interest Convergence in the Superhero Film. The Journal of American Culture, 40(2), 155-168.

Kendall, L. (2002). Hanging out in the virtual pub : masculinities and relationships online. University of California Press. Retrieved from http://www.ucpress.edu/book.php?isbn=9780520230385 
Massanari, A. (2017). \# Gamergate and The Fappening: How Reddit's algorithm, governance, and culture support toxic technocultures. New Media \& Society, 19(3), 329346.

Mendelson, S. (2018, February). Box Office: 'Black Panther' Tops 'Spider-Man,' Will Pass 'Wonder Woman' Today. Forbes.

https://www.forbes.com/sites/scottmendelson/2018/02/27/box-office-black-panther-topsspider-man-will-pass-wonder-woman-today/\#18c8b0517646.

Plante, C. (2018, February). 'The Last Jedi' Rotten Tomatoes Hacker Targets 'Black Panther.' Inverse. https://www.inverse.com/article/40800-black-panther-rottentomatoes-dc-fan-hacker-event.

Romano, A. (2018, February). Racist trolls are saying Black Panther fans attacked them. They're lying. Vox. https://www.vox.com/culture/2018/2/16/17020230/blackpanther-movie-theater-attacks-fake-trolls.

Salter, A., \& Blodgett, B. (2012). Hypermasculinity \& dickwolves: The contentious role of women in the new gaming public. Journal of broadcasting \& electronic media, 56(3), 401-416.

Salter, A., \& Blodgett, B. (2017). Toxic Geek Masculinity in Media: Sexism, Trolling, and Identity Policing. Springer.

Walsh, H. (2017). Have Disney strike Star Wars Episode VIII from the official canon. Change.org. https://www.change.org/p/the-walt-disney-company-have-disney-strikestar-wars-episode-viii-from-the-official-canon.

Yin, R. K. (2003). Case study methodology R.K. Yin (2003, 3rd edition). Case Study Research design and methods. Sage, Thousand Oaks (CA)..pdf. In Case Study Research: design and methods (pp. 19-39-106). 